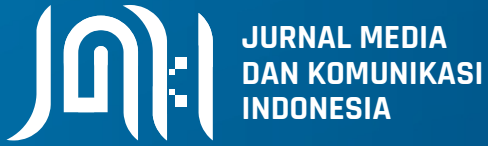

92 Strategi Penyusunan Pesan Informatif - Persuasif Dalam Data Covid-19 Oleh Humas Diskominfo Kota Bogor di Media Sosial

Shafa Tsamara Nugraini, Abdul Kholik

104 Strategi Redaksi Catch Me Up! Dalam Menghadapi Persaingan Industri Media Online

Aaron Reghanada Prasetyawibowo, Ni Made Ras Amanda Gelgel, I Gusti Agung Alit Suryawati

115 Permainan Simulasi Kencan sebagai Medium Romantic Loneliness

131 Pengaruh Kredibilitas, Kualitas Pendekatan Emosional, Dan Kualitas Isi Pesan Terhadap Efektivitas Kampanye "Love Myself" Antonia Meme 148 Informasi Kinerja Pemerintah Daerah di Media Online 


\section{Jurnal Media dan Komunikasi Indonesia}

Jurnal Media dan Komunikasi (JMKI) diterbitkan Departemen Ilmu Komunikasi, Fakultas IImu Sosial dan IImu Politik, Universitas Gadjah Mada. Terbit dua kali setahun, Maret dan September. JMKI dedikasikan untuk mempublikasikan dan mendiseminasikan penelitian, kajian, dan fenomena dalam IImu Komunikasi khususnya di Indonesia. Ruang lingkup manuskrip yang diterbitkan di JMKI adalah manifestasi dari visi Departemen Ilmu Komunikasi yaitu "Crafting Well Informed Society." JMKI mengundang para peneliti maupun praktisi dari berbagai disiplin keilmuan untuk menulis tentang kajian media dan komunikasi seperti jurnalisme dan media, media entertainment, periklanan, humas, cultural studies, film studies, dan game studies.

\section{Editor in Chief}

Rajiyem, Faculty of Social and Political Sciences Universitas Gadjah Mada

\section{Deputy Editor in Chief}

I Gusti Ngurah Putra, Faculty of Social and Political Sciences Universitas Gadjah Mada

\section{Editorial Board}

Wisnu Prasetya Utomo, Faculty of Social and Political Sciences Universitas Gadjah Mada

Widodo Agus Setianto, Faculty of Social and Political Sciences Universitas Gadjah Mada

\section{Reviewer}

Muninggar Saraswati, Swiss German University

Gregoria Arum Yudarwati, Universitas Atma Jaya

Rajab Ritonga, Faculty of Communication Science, Universitas Prof. Dr. Moestopo (Beragama)

Effendi Gazali, Universitas Prof. Dr. Moestopo (Beragama)

Megandaru Widhi Kawuryan, Departement of Government, Institut Pemerintahan Dalam Negeri (IPDN)

Hermin Indah Wahyuni, Faculty of Social and Political Sciences, Universitas Gadjah Mada

Novi Kurnia, Faculty of Social and Political Sciences, Universitas Gadjah Mada

Nunung Prajarto, Faculty of Social and Political Sciences, Universitas Gadjah Mada

\section{Editorial Secretary}

Jusuf Ariz Wahyuono, Faculty of Social and Political Sciences Universitas Gadjah Mada

\section{Mailing Address}

Departemen Ilmu Komunikasi

Jalan Sosio Yustisia No. 2 Bulaksumur

Yogyakarta 55281

Email:jmki@ugm.ac.id 


\section{Daftar ISI}

Strategi Penyusunan Pesan Informatif - Persuasif Dalam Data Covid-19 Oleh Humas Diskominfo Kota Bogor di Media Sosial

Shafa Tsamara Nugraini, Abdul Kholik

Strategi Redaksi Catch Me Up! Dalam Menghadapi Persaingan Industri Media Online

Aaron Reghanada Prasetyawibowo, Ni Made Ras Amanda Gelgel, I Gusti Agung Alit Suryawati

Permainan Simulasi Kencan sebagai Medium Romantic Loneliness

Sarah Noverianti, Ardian Indro Yuwono

Pengaruh Kredibilitas, Kualitas Pendekatan Emosional, Dan Kualitas Isi Pesan Terhadap Efektivitas Kampanye "Love Myself"

Antonia Meme

Informasi Kinerja Pemerintah Daerah di Media Online

Nur Imroatus Sholikhah 


\title{
Pengaruh Kredibilitas, Kualitas Pendekatan Emosional, Dan Kualitas Isi Pesan Terhadap Efektivitas Kampanye "Love Myself"
}

\author{
Antonia Meme
}

\author{
| Magister Ilmu Komunikasi, Universitas Atma Jaya Yogyakarta \\ Bisa dihubungi melalui email: antoniameme.09@gmail.com
}

\section{ABSTRAK}

A successful social campaign was created from elements such a specific targeted audience, campaign messages, developed theory of change, and use a proper communicator. The elements formulated in the rhetoric theory: credibility, emotions, messages. The elements were conducted in a campaign called "Love Myself" by BTS, a K-pop group. This study was conducted to figure out the effect of credibility, the quality of the emotional approach, and the quality of the messages from K-pop group BTS on the effectiveness of the campaign "Love Myself". This study uses a rhetoric theory that focuses on the aspects of ethos (credibility), pathos (emotions), and logos (logic). This study uses a survey method, especially an online questionnaire. Non-probability sampling is a sampling technique where not every population has a chance to become a sample. Quota sampling where the quota set first by the researcher. The population is total followers of Twitter account @armyindonesiaa2 and the number of sampling, 395. The analysis technique uses path analysis. The result presents the final model where six relation variables are not significant. Based on the test model, the final model is no longer suitable for use as a research model compared to the hypothetical model. The largest total effect result, forming from variable effectiveness of the campaign "Love Myself". The process of this research concluded that the credibility and emotional approach of K-pop group BTS has no contribution to the effectiveness of the campaign "Love Myself".

Keywords: credibility, emotional approach, messages, effectiviness campaign

\section{Pendahuluan}

Kampanye \#LoveMyself didasarkan pada fakta kekerasan disiplin yang dilakukan oleh orang tua terhadap anak. Kekerasan, baik secara fisik ataupun emosional dialami 300 juta anak-anak di dunia umur 2-4 tahun. Selain itu, 6 dari 10 atau sekitar 250 juta anak-anak mengalami hukuman fisik. Fakta ini dipaparkan dalam United Nations Children's Fund (UNICEF), A Familiar Face: Violence in the lives of children and adolescents
(UNICEF, 2017).

Kekerasan terhadap anak yang merupakan bentuk penganiayaan kepada anakanak berusia di bawah 18 tahun termasuk kekerasan fisik, emosional, seksual, dan eksploitasi. Kekerasan pada anak berdampak pada kesehatan, ketahanan hidup, atau pembangunan anak-anak. Fakta kunci berkaitan dengan kekerasan anak, setidaknya empat orang dewasa 
melaporkan bahwa dirinya merupakan korban kekerasan fisik pada saat mereka anak-anak dan $36 \%$ melaporkan bahwa dirinya merupakan korban kekerasan emosional pada saat mereka anak-anak (WHO, 2014).

Sebanyak 73,7\% anak-anak di Indonesia yang berumur 1-14 tahun mengalami pendisiplinan dengan kekerasan atau agresi psikologis dan hukuman fisik di rumah. Komisi Perlindungan Anak Indonesia (KPAI) mencatat sebanyak 4.294 kasus kekerasan pada anak dilakukan oleh keluarga dan pengasuh (20112016). Sebanyak 931 kasus kekerasan terjadi pada tahun 2013, 921 di tahun 2014, 822 di tahun 2015, dan 571 kasus di tahun 2016 (www.tirto.id)

Dampak kekerasan yang dapat mempengaruhi kehidupan sosial ataupun munculnya masalah kesehatan, kampanye \#ENDViolence bertujuan untuk memberikan jaminan kepada anak-anak dan remaja di dunia agar hidup aman dan sehat tanpa takut akan mengalami kekerasan. Sedangkan pemilihan LOVE MYSELF karena BTS sejak debut pada tahun 2013 secara terus-menerus berfokus memberikan pesan yang menenangkan untuk kaum muda. Salah satu pesan dalam kampanye LOVE MYSELF "find love in myself, embrace people and society in a larger sense of love". BTS mengajak kaum muda untuk menemukan cinta kasih dalam dirinya sendiri dan mengupayakan berbagi kasih kepada orang dan lingkungan dengan cinta (lovemyself.org).

BTS semenjak debut secara konsisten menyuarakan terkait keresahan dan ketakutan yang dirasakan generasi muda. BTS menghargai keberagaman dan keadilan, kebenaran untuk generasi muda dan memperhatikan anak muda yang terpinggirkan karena isu sosial (time.com). Berdasarkan perjalanan karir yang tidak mudah dan ingin secara konsisten menyuarakan tentang isu sosial, pada 1 November 2017, K-pop Grup BTS menjadi sponsor kampanye global UNICEF \#ENDViolence, kaitannya dengan kampanye global ini BTS mengkreasikan dan memulai gerakan yang dinamakan "Love Myself". Kampanye \#LoveMyself bertujuan untuk menciptakan dan menyebarkan kasih serta kehidupan yang lebih baik untuk anak-anak dan remaja. BTS dan penggemarnya di seluruh dunia selama ini telah berusaha untuk mengangkat dan menyuarakan tentang isu-isu sosial. (lovemyself.org).

BTS memulai gerakan "Love Myself" dengan menggunakan tagar \#BTSLoveMyself di Twitter. Sampai dengan 10 Juli 2019 tagar \#BTSLoveMyself telah digunakan sebanyak 10.463.503 oleh pengguna Twitter (lovemyself.org,). BTS dikenal sebagai K-pop grup yang aktif menjalin hubungan dengan penggemar melalui Twitter. Pengikut akun @bts_twt sudah lebih dari 37 juta pengikut. Fanbase BTS di media sosial khususnya di Indonesia adalah akun Twitter @armyindonesiaa2. Berdasarkan data per tanggal 11 Juli 2019 akun Twitter @armyindonesiaa2 telah diikuti lebih dari 35.000 pengikut (twitter.com/armyindonesiaa2).

Menurut Dina Andriandini, Client Executive Burson-Marstellar (BCW Global), publik menggunakan Twitter untuk mencari informasi secara real time dengan sifat twitter yang live dan coversational. Publik berpartisipasi dalam beragam topik yang menjadi tren di linimasa. Bagi 
para penggemar K-pop, twitter menjadi wadah yang penting untuk lebih terhubung dengan idolanya serta bertukar informasi dengan komunitas penggemar. Tahun 2018, akun Twitter @bts_twt menjadi jajaran nomer pertama yang paling banyak dibicarakan oleh pengguna di Indonesia dan tagar \#BTS menjadi tagar nomer pertama yang paling banyak digunakan oleh pengguna di Indonesia (www.tirto.id). Hal inilah yang menjadikan kampanye \#LoveMyself oleh Kpop grup BTS dimulai di twitter karena penggemar dapat terhubung dengan BTS dan isu kekerasan melalui tagar \#LoveMyself \#ENDViolence.

BTS yang secara konsisten menyuarakan isu-isu sosial bertolak belakang dengan label yang diberikan kepada penggemarnya. Dalam ranah Kpop setiap grup idola K-Pop memiliki penggemar dengan julukan berbeda, biasa disebut fandom. Suatu wilayah dengan jumlah fandom besar bisa dikategorikan sebagai fanbase (www.tirto.id). Fandom dari K-pop grup BTS dinamakan ARMY singkatan dari Adorable Representative M.C for Youth. ARMY diberi label sebagai fandom yang toxic atau "beracun". Toxic atau "beracun" ditujukan pada perilaku negatif ARMY kepada sesama penggemar atau penggemar grup lain. Salah satu perilaku negatif yang dimaksud adalah melontarkan kata-kata yang kurang sopan dan bermoral atau melakukan perdebatan di media sosial kepada penggemar atau pengguna media sosial yang melontarkan kritik ke BTS (www.sanepo.com).

Hal yang bertolak belakang antara K-pop grup BTS yang konsisten menyuarakan isu sosial dan ARMY yang dilabeli sebagai fandom "beracun" membuat peneliti tertarik untuk meneliti pengaruh K-pop Grup BTS terhadap kampanye \#LoveMyself kepada penggemarnya, ARMY. Pengaruh yang dimaksud dalam penelitian ini berfokus pada aspek retorika yang dikemukakan oleh Aristoteles yaitu ethos (kredibilitas), pathos (emosi), dan logos (bukti). BTS sebagai penyampai pesan dalam kampanye \#LoveMyself harus memiliki kredibilitas, sisi emosional, dan bukti rasional yang akan disampaikan dan ditunjukkan terkait kampanye ini.

Kredibilitas ini disebut ethos. Ethos merujuk pada karakter, intelegensi, dan niat baik yang dipersepsikan dari seorang pembicara atau pengirim pesan (West \& Turner, 2014: 7). Kredibilitas sumber biasa digunakan untuk mendeskripsikan pengaruh positif dari pesan komunikasi kepada penerima. Kredibilitas memiliki peran penting dalam memberikan efek komunikasi persuasi dari komunikator kepada komunikan agar membawa perubahan sosial (Salmon \& Murray-Johnson, 2001 dalam Rice \& Atkin, 2013: 100).

Sisi emosional atau pathos mempunyai kemampuan untuk mengkreasikan kepemilikan emosional melalui kata-kata dan pendekatan kepada audiens melalui identitas dan ketertarikan individu (Ramage, Bean \& Johnson, 2012: 83). Memicu sisi emosional audiens merupakan suatu hal yang penuh kuasa di mana audiens mendapatkan suatu keinginan melalui pesan yang disampaikan. Aristoteles menyatakan bahwa pathos tidak disalahgunakan atas perubahan emosional audiens namun sebagai pengukuran yang dapat membantu komunikator untuk bukti emosional yang menginspirasi audiens dalam 
pembuatan keputusan (Griffin, Ledbetter, \& Sparks, 2015: 288).

Bukti yang disebut logos dapat diartikan sebagai argumen dan rasionalitas. Logos mengarahkan pada persuasi melalui pesan-pesan yang rasionalitas dan kejelasan pesan yang disampaikan (Ramage, Bean,\& Johnson, 2012: 85). Melalui logos, komunikator dapat membuktikan pentingnya pesan kampanye. Logos juga berhubungan dengan konsistensi pesan kampanye yang dapat memicu kepekaan audiens terhadap isu yang sedang dikampanyekan (Ramage, Bean \& Johnson, 2012: 85). Aristoteles menyatakan bahwa masing-masing elemen ethos, pathos, dan logos merupakan hal penting agar pesan yang disampaikan komunikator menjadi efektif (West \& Turner, 2014: 315).

Menurut Muyasaroh (2013) bahwa persoalan mengenai kesadaran manusia, atau lebih tepatnya kesadaran individu sebagai akar kesadaran masyarakat merupakan suatu hal yang sudah lama didiskusikan, bahkan menjadi fenomena publik yang tanpa henti. Muyasaroh juga menjelaskan bahwa terdapat perspektif individu dan perspektif sosio kultural yang mempengaruhi perubahan perilaku setiap individu atau khalayak. Hal ini mengartikan bagaimanapun hebatnya penyampaian pesan dengan sederetan kredibilitas yang dimiliki terkadang tidak sesuai dengan apa yang diharapkan.

Terdapat beberapa penelitian yang dijadikan acuan oleh peneliti. Penelitian terdahulu yang dijadikan acuan berkaitan dengan tiga elemen dalam teori retorika.

Penelitian pertama yang dilakukan oleh
Byrum (2014) dengan judul "A Comparison Of The Source, Media Format, And Sentiment In Generating Source Credibility, Information Credibility, Corporate Brand Reputation, Purchase Intention, And Social Media Engagement In A Corporate Social Responsibility Campaign Presented Via Social Media". Penelitian ini tentang dampak sumber, format media, dan sentimen yang mempengaruhi kredibilitas sumber, kredibilitas informasi, reputasi merek perusahaan, intensi membeli, dan keterikatan di media sosial dalam kampanye corporate social responsibility (CSR) yang dilakukan di media sosial.

Hasil penelitian menyatakan bahwa ada perbedaan yang signifikan sumber, format media, dan sentimen yang menstimulasi aspek kredibilitas sumber, kredibilitas informasi, reputasi merek perusahaan, dan intensi membeli ketika mempertimbangkan sumber dan sumber/format/sentimen interaksi.

Penelitian yang dilakukan oleh Byrum berkaitan dengan kawasan studi Public Relations tentang CSR dari berbagai aspek yang dijadikan variabel penelitian. Salah satu variabel berkaitan dengan kredibilitas sumber. Peneliti dalam penelitian ini menggunakan pengembangan kredibilitas sumber untuk melihat pengaruh komunikator kampanye sosial UNICEF \#ENDViolence "Love Myself" yaitu BTS dalam mempengaruhi perubahan perilaku audiens.

Penelitian kedua yang dilakukan oleh Howard (2017) dengan judul "Tweeting Is Easy, Rhetoric's Harder: A Rhetorical Analysis Of Public Political Discourse On Social Media". Penelitian ini tentang para politikus dan masyarakat Amerika 
menggunakan media sosial untuk mendiskusikan politik. Penelitian berkaitan dengan interaksi 4 unggahan yang berbeda melalui Twitter dan Facebook menggunakan analisis retorika Aristoteles untuk menentukan bagaimana pengguna media sosial ikut serta dalam persuasi retorika

Penelitian yang dilakukan oleh Howard berkaitan dengan kawasan studi komunikasi politik tentang retorika politik melalui media sosial. Hasil dari penelitian menunjukkan bahwa media sosial memberikan akses kepada setiap individu untuk dapat ikut serta dalam diskusi yang memiliki tujuan dan bersifat persuasif. Peneliti dalam penelitian ini menggunakan media sosial untuk melihat pengaruh komunikator kampanye sosial UNICEF \#ENDViolence "Love Myself" yaitu BTS dalam mempengaruhi perubahan perilaku target audiens.

Penelitian ketiga yang dilakukan oleh Sanjaya, Biyoga, dan Alunaza (2017) dengan judul "Pemimpin Minoritas dan Strategi Retorika Pathos dalam Kampanye: Analisis Isi Deskriptif Pesan Strategi Retorika dalam Facebook Kampanye Pemilihan Gubernur". Penelitian ini tentang kelompok minoritas yang sering berbenturan dengan etnis atau isu agama namun tidak sedikit pemimpin dari kelompok minoritas yang berhasil terpilih sebagai eksekutif politik. Pemimpin minoritas menggunakan strategi khas selama kampanye politik yang cenderung menggunakan pendekatan irasional dibandingkan pendekatan rasional.

Penelitian ini analisis isi (kualitatif) dan peneliti menggunakan metode survei (kuantitatif), namun penelitian sebelumnya lebih fokus ke pathos sedangkan peneliti menggunakan ethos, pathos, dan logos untuk penelitian yang akan dilakukan.

Mengacu pada kritik dan penutup teori retorika Aristoteles (West \& Turner, 2014: 19) dalam penelitian ini dari sisi heuristik untuk mengeksplorasi topik dan membangun argumen penelitian yang menggunakan teori retorika. Sisi konsistensi logis memberikan pandangan tentang khalayak yang aktif; menonton dan membaca berita serta memiliki akses terhadap informasi mengenai kejadian di seluruh dunia. Sisi pengujian waktu berjalan, teori yang berfokus pada pembicara menggunakan emosi, logika, dan kepercayaan ini masih tetap relevan dan tidak bisa diabaikan di era digital.

Berdasarkan pemaparan latar belakang di atas peneliti tertarik untuk meneliti pengaruh kredibilitas, kualitas pendekatan emosional, dan kualitas isi pesan K-pop grup BTS terhadap efektivitas kampanye "Love Myself" di akun Twitter@armyindonesiaa2 dengan variabel antara pada kategorisasi penggemar yang dimaksudkan untuk melihat apakah variabel antara mempengaruhi atau tidak mempengaruhi keputusan untuk melakukan donasi.

\section{METODE}

Jenis penelitian yang digunakan adalah penelitian kuantitatif. Tipe penelitian eksplanatif (explanative research). Metode yang digunakan adalah metode survei. Penelitian ini populasinya adalah seluruh pengikut akun Twitter @armyindonesiaa2 dengan jumlah 35.164 pengikut per tanggal 11 Juli 2019. 
Teknik sampling yang digunakan adalah non-probability sampling. Kerangka sampel dalam penelitian ini daftar nama akun pengikut Twitter @armyindonesiaa2 yang terletak pada kolom followers. Teknik sampling yang digunakan adalah kuota sampling.

Kuesioner dalam penelitian ini berbentuk kuesioner online yang akan dibagikan kepada responden (pengikut akun @armyindonesiaa2) melalui Twitter. Analisa data menggunakan analisis jalur yang merupakan teknik statistik yang digunakan untuk melihat hubungan kausal antara 2 atau lebih variabel. Sewall Wright mengembangkan analisis jalur termasuk koefisien jalur dan menggunakan peraturan perkalian untuk menentukan hubungan tidak langsung antara satu variabel dengan variabel lainnya (Olobatuyi, 2006:4)

\section{Hasil dan Pembahasan}

Analisis jalur digunakan untuk memahami perbandingan kekuatan hubungan langsung (direct relationship) dan hubungan tidak langsung (indirect relationship) dari serangkaian variabel dalam penelitian sehingga temuan yag didapat tidak hanya bersifat prediktif tetapi lebih jauh memberikan penjelasan terhadap hubungan antar variabel (Herawati, 2004: 212). Berdasarkan hipotesis model hubungan variabel-variabel penelitian maka variabel eksogen dalam penelitian ini adalah kredibilitas (ethos), kualitas pendekatan emosional (pathos), dan kualitas isi pesan (logos) K-pop grup BTS. Variabel endogen dalam penelitian ini adalah efektivitas kampanye "Love Myself" dan variabel antara (disebut variabel prediktor dalam analisis jalur) adalah kategorisasi penggemar. Menurut Herawati (2014: 217) variabel prediktor adalah variabelvariabel yang dapat mempengaruhi variabel endogen. Variabel prediktor dapat berupa variabel eksogen ataupun variabel endogen lain. Dalam penelitian ini variabel prediktor menjadi variabel endogen dalam perhitungan data nantinya.

Pengujian analisis regresi didasarkan pada variabel endogen yang ada dalam hipotesis model hubungan antar variabel. Variabel endogen akan menjadi variabel dependen dan variabel eksogen akan menjadi variabel independen. Analisis jalur berkaitan erat dengan analisis regresi berganda. Regresi berganda adalah kasus khusus dari analisis jalur, berkaitan dengan model hubungan sebab akibat karena analisis jalur memungkinkan untuk menguji proposisi teoritis tentang sebab dan akibat tanpa memanipulasi variabel. Analisis jalur adalah bentuk yang lebih sepesifik, analisis yang dilihat secara eksplisit pada suatu kasus. Hal tersebut yang tidak bisa digunakan secara ketat oleh analisis regresi, baik tunggal ataupun ganda (Herawati, 2014: 212)

Perhitungan akan dilakukan dengan menggunakan program SPSS statistics 25 dengan uji regresi terhadap variabel endogen. Tahapantahapan analisis jalur dalam penelitian ini sebagai berikut.

\section{Menentukan Hipotesis Model}

Penelitian ini menggunakan teori-teori sebagai berikut: pertama, teori retorika sebagai teori utama dalam penelitian. Kedua, teori komunikasi persuasi untuk menjelaskan area penelitian. Ketiga, teori kampanye 
komunikasi untuk menjelaskan penggunaan retorika dan persuasi dalam ranah kampanye. Keempat, teori kampanye online untuk menjelaskan ranah kampanye dalam penelitian ini. Kelima, teori penggemar untuk menjelaskan posisi responden di penelitian ini. Bedasarkan teori-teori tersebut maka munculah hipotesis model yang ditentukan oleh peneliti berdasarkan hubungan antar variabel-variabel dalam penelitian yang digambarkan dalam bagan berikut.

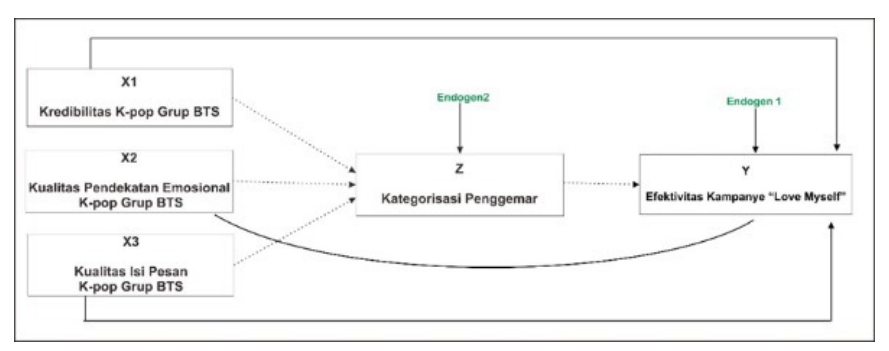

Bagan 1 Hipotesis Model

\section{Uji Hipotesis}

Pengujian analisis regresi didasarkan pada variabel endogen yang ada dalam hipotesis model hubungan antar variabel. Uji regresi pertama untuk mengetahui bagaimana pengaruh variabel kredibilitas $\left(X_{1}\right)$, kualitas pendekatan emosional $\left(\mathrm{X}_{2}\right)$, kualitas isi pesan K-pop Grup BTS $\left(\mathrm{X}_{3}\right)$, dan variabel kategorisasi penggemar ( $Z$ ) terhadap variabel efektivitas kampanye "Love Myself" ( $Y$ ) atau variabel endogen satu $\left(\mathrm{e}_{1}\right)$.

\begin{tabular}{|l|r|r|}
\hline $\begin{array}{c}\text { Model } \\
\text { Constant }\end{array}$ & \multicolumn{1}{c|}{ Beta } & \multicolumn{1}{c|}{ Sig } \\
\hline X1 & $\mathbf{, 0 3 9}$ & $\mathbf{, 4 4 7}$ \\
\hline X2 & $\mathbf{0 7 8}$ & $\mathbf{, 1 3 0}$ \\
\hline X3 & $\mathbf{1 9 3}$ & $\mathbf{, 0 0 0}$ \\
\hline Z & $\mathbf{- , 0 3 2}$ & $\mathbf{, 5 1 7}$ \\
\hline \multicolumn{3}{|l|}{ Dependent Variable: $\mathrm{Y}$} \\
\hline
\end{tabular}

Sumber: SPSS Statistics 25

Hasil uji regresi pertama menunjukkan bahwa kontribusi variabel kredibilitas K-pop Grup BTS $\left(X_{1}\right)$ terhadap terbentuknya variabel efektivitas kampanye "Love Myself" ( $Y$ ) sebesar 0,039 (nilai beta) dan hubungan tidak signifikan (Sig. 0,447>0,05). Kontribusi variabel kualitas pendekatan emosional K-pop Grup BTS $\left(X_{2}\right)$ terhadap terbentuknya variabel efektivitas kampanye "Love Myself" (Y) sebesar 0,078 dan hubungan tidak signifikan (Sig. 0,130>0,05). Kontribusi variabel kualitas isi pesan K-pop Grup BTS $\left(\mathrm{X}_{3}\right)$ terhadap terbentuknya variabel efektivitas kampanye "Love Myself" (Y) sebesar 0,193 dan hubungan signifikan (Sig. 0,000 $<0,05$ ). Sedangkan kontribusi dari variabel kategorisasi penggemar (Z) terhadap terbentuknya variabel efektivitas kampanye "Love Myself" (Y) sebesar - 0,032 dan hubungan tidak signifikan (Sig. 0,517>0,05). 
Tabel 2 Model Summary dan Anova Uji Regresi Pertama

\section{Summary}

\begin{tabular}{|c|r|}
\hline \multicolumn{1}{|l|}{$\mathbf{R}$} & \multicolumn{1}{|c|}{ R Square } \\
\hline $\mathbf{2 2 9}^{\mathbf{a}}$ &, 053 \\
\hline
\end{tabular}

ANOVA $^{a}$

\begin{tabular}{|c|c|}
\hline $\mathbf{F}$ & Sig. \\
\hline 5,414 & $\mathbf{0 0 0}^{\mathbf{b}}$ \\
\hline
\end{tabular}

Sumber: SPSS Statistics 25

Berdasarkan penggolongan tersebut maka kekuatan hubungan variabel kredibilitas $\left(X_{1}\right)$, variabel kualitas pendekatan emosional $\left(X_{2}\right)$, variabel kualitas isi pesan K-pop Grup BTS $\left(X_{3}\right)$ dan variabel kategorisasi penggemar $(\mathrm{Z})$ terhadap variabel efektivitas kampanye "Love Myself" (Y) adalah lemah. Hal ini dilihat dari nilai R sebesar 0,229 dan signifikansi 0,000.

Uji regresi kedua untuk mengetahui bagaimana pengaruh variabel kredibilitas $\left(X_{1}\right)$, kualitas pendekatan emosional $\left(X_{2}\right)$, kualitas isi pesan K-pop Grup BTS $\left(X_{3}\right)$ terhadap variabel kategorisasi penggemar (Z) atau variabel endogen dua $\left(e_{2}\right)$.

Tabel 3 Uji Regresi Kedua

\begin{tabular}{|l|r|r|}
\hline $\begin{array}{c}\text { Model } \\
\text { Constant }\end{array}$ & \multicolumn{1}{c|}{ Beta } & \multicolumn{1}{c|}{ Sig } \\
\hline X1 & $\mathbf{, 0 2 6}$ & $\mathbf{6 2 3}$ \\
\hline X2 & $\mathbf{0 0 9}$ & $\mathbf{, 8 6 2}$ \\
\hline X3 & $\mathbf{0 4 8}$ & $\mathbf{, 3 6 5}$ \\
\hline \multicolumn{2}{|l|}{ Dependent Variable: Z } \\
\hline
\end{tabular}

Sumber: SPSS Statistics 25
Hasil uji regresi kedua menunjukkan bahwa kontribusi variabel kredibilitas K-pop Grup BTS $\left(\mathrm{X}_{1}\right)$ terhadap terbentuknya variabel kategorisasi penggemar (Z) sebesar 0,026 (nilai beta) dan hubungan tidak signifikan (Sig. $0,623>0,05)$. Kontribusi variabel kualitas pendekatan emosional K-pop Grup BTS $\left(\mathrm{X}_{2}\right)$ terhadap terbentuknya variabel kategorisasi penggemar (Z) sebesar 0,009 dan hubungan tidak signifikan (Sig. 0,862>0,05). Kontribusi variabel kualitas isi pesan K-pop Grup BTS $\left(X_{3}\right)$ terhadap terbentuknya variabel kategorisasi penggemar (Z) sebesar 0,048 dan hubungan signifikan (Sig. 0,862>0,05).

Tabel 4 Model Summary dan Anova Uji Regresi Kedua

\begin{tabular}{|l|r|}
\hline $\mathbf{R}$ & R Square \\
\hline, $059^{\mathbf{a}}$ &, 003 \\
\hline
\end{tabular}

Summary

ANOVA $^{a}$

\begin{tabular}{|c|c|}
\hline F & Sig. \\
\hline, 452 & $\mathbf{7 1 6}^{\mathbf{b}}$ \\
\hline
\end{tabular}

Sumber: SPSS Statistics 25

Kekuatan hubungan variabel kredibilitas $\left(X_{1}\right)$, variabel kualitas pendekatan emosional $\left(X_{2}\right)$, dan variabel kualitas isi pesan K-pop Grup BTS $\left(X_{3}\right)$ terhadap variabel kategorisasi penggemar ( $Z$ ) adalah sangat lemah. Hal ini dilihat dari nilai $R$ sebesar 0,059 dan signifikansi 0,716.

3. Menghilangkan Hubungan Tidak Signifikan di Hipotesis Model 
Tabel 5 Uji Regresi Kedua

Analisis regresi pada tahap 2 dihasilkan jika hanya satu hubungan yang signifikan yaitu hubungan antara variabel kualitas isi pesan Kpop Grup BTS $\left(\mathrm{X}_{3}\right)$ terhadap variabel efektivitas kampanye "Love Myself" (Y) (Sig. 0,000 < $0,05)$, selain daripada ini hubungan antar variabel dengan variabel lainnya tidak signifikan. Pada model yang disesuaikan hubungan yang tidak signifikan akan dihilangkan dari model ditandai dengan garis putus-putus dan hubungan yang signifikan akan ditandai dengan garis utuh.

Bagan 2 Model yang Disesuaikan

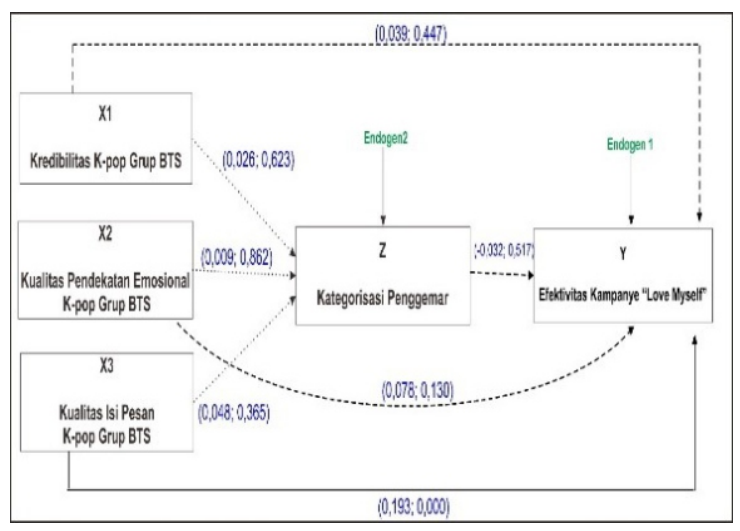

4. Uji Regresi Ulang Model yang Disesuaikan

Uji regresi ulang dilakukan seperti tahap 2 namun pada tahap ini hanya terhadap hubungan yang signifikan maka uji regresi ulang akan dilakukan satu kali yaitu hubungan variabel kualitas isi pesan K-pop Grup BTS $\left(\mathrm{X}_{3}\right)$ terhadap variabel efektivitas kampanye "Love Myself" maka uji regresi ulang untuk mengetahui bagaimana pengaruh variabel kualitas isi pesan K-pop Grup BTS $\left(\mathrm{X}_{3}\right)$ terhadap variabel efektivitas kampanye "Love Myself" $(\mathrm{Y})$ atau variabel endogen satu $\left(\mathrm{e}_{1}\right)$.

\begin{tabular}{|l|c|c|}
\hline $\begin{array}{c}\text { Model } \\
\text { Constant }\end{array}$ & Beta & Sig \\
\hline X3 & $\mathbf{2 1 3}$ & $\mathbf{, 0 0 0}$ \\
\hline \multicolumn{4}{|l|}{ Dependent Variable: $Y$} \\
\hline
\end{tabular}

Sumber: SPSS Statistics 25

Hasil uji regresi ulang kedua menunjukkan bahwa kontribusi variabel kualitas isi pesan $\mathrm{K}$ pop Grup BTS $\left(X_{3}\right)$ terhadap variabel efektivitas kampanye "Love Myself" (Y) sebesar 0,213 dan hubungan tersebut tetap signifikan $(0,000$ $<0,05)$.

\section{Tabel 6 Model Summary dan Anova Uji} Regresi Ulang

Summary ${ }^{\mathrm{b}}$

\begin{tabular}{|c|c|}
\hline $\mathbf{F}$ & Sig. \\
\hline 18,723 & $\mathbf{0 0 0}^{\mathbf{b}}$ \\
\hline
\end{tabular}

ANOVA $^{a}$

\begin{tabular}{|c|r|}
\hline \multicolumn{1}{|l|}{$\mathbf{R}$} & \multicolumn{1}{|c|}{ R Square } \\
\hline $\mathbf{2 1 3}^{\mathbf{a}}$ &, 045 \\
\hline
\end{tabular}

Sumber: SPSS Statistics 25

Kekuatan hubungan variabel kualitas isi pesan K-pop Grup BTS $\left(\mathrm{X}_{3}\right)$ terhadap variabel efektivitas kampanye "Love Myself" ( $\mathrm{Y}$ ) adalah lemah. Hal ini dilihat dari nilai R sebesar 0,213 dan signifikansi 0,000.

\section{Model Akhir}

Berdasarkan hasil uji regresi ulang maka model akhir hubungan antar variabel dalam penelitian ini sebagai berikut. 


\section{Bagan 3 Model Akhir}

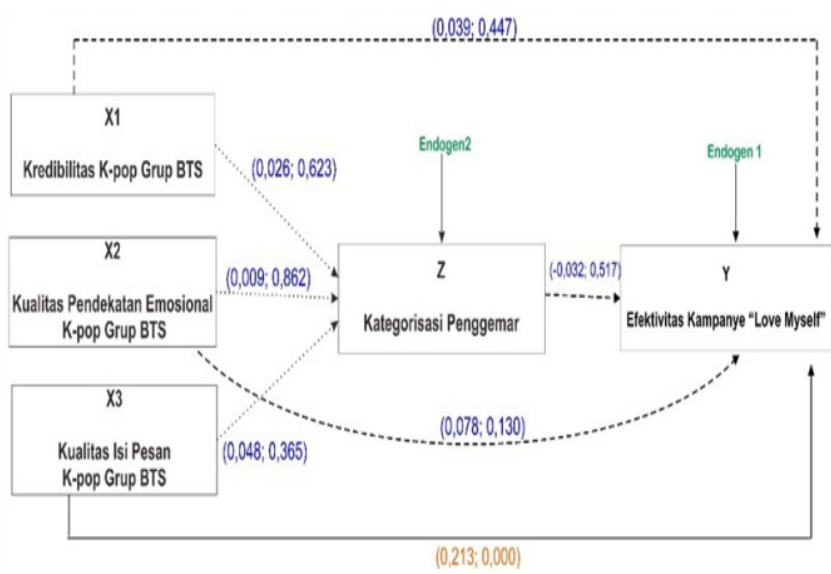

\section{Pengujian Model}

Pengujian model dilakukan untuk melihat apakah model akhir dalam penelitian lebih baik daripada hipotesis model. Pengujian dilakukan dengan menghitung fit coefficient secara manual berdasarkan rumus dari Kline (Herawati, 2004: 228).

Fit Coefficient (Nilai $\chi_{Q}^{2}$ )

$\chi_{Q}^{2}=(N-d f) \log Q$

$$
\begin{aligned}
& =(395-6) \log 1,02075227 \\
& =389 \times\left(8,920354402 \times 10^{-3}\right) \\
& =3,470
\end{aligned}
$$

$$
\chi_{\text {tabel }}^{2} 0.05(1) \quad=3,841
$$

Berdasarkan hasil penghitungan fit coefficient secara manual didapatkan $\chi_{a}^{2}$ $(3,470)<\chi_{\text {tabel }}^{2}(3,841)$. Artinya secara statistik model akhir tidak signifikan menjadi model fit yang lebih baik dari hipotesis model.

\section{Menghitung dan Menganalisis Komposisi} Hubungan: Direct Effect, Indirect Effect, dan Total Effect
Total effect adalah penjumlahan dari efek langsung dan efek tidak langsung dan yang terbesar adalah total effect untuk membentuk variabel efektivitas kampanye "Love Myself" (Y) sebesar 0,295344.

\section{PEMBAHASAN}

Pertama $X_{1} \rightarrow Y$, hubungan antara variabel kredibilitas K-pop Grup BTS $\left(X_{1}\right)$ terhadap variabel efektivitas kampanye $(Y)(\beta=0,039$ dan Sig. 0,447). Nilai signifikansi lebih dari 0,05 yang artinya hipotesis penelitian $\mathrm{H}_{\mathrm{o}}$ diterima, tidak ada pengaruh kredibilitas K-pop Grup BTS terhadap efektivitas kampanye "Love Myself" dan $\mathrm{H}_{\mathrm{a}}$ ditolak, ada pengaruh kredibilitas K-pop Grup BTS terhadap efektivitas kampanye "Love Myself" sehingga hubungan kedua variabel tersebut tidak signifikan.

Hubungan yang tidak signifikan antara variabel kredibilitas K-pop Grup BTS terhadap variabel efektivitas kampanye "Love Myself" karena kredibilitas merupakan tahap penilaian dari penerima pesan terhadap komunikator, penilaian karakteristik yang diterima audiens kepada komunikator. Secara teori menurut Lumsden \& Lumsden (2006: 27) kredibilitas terletak pada pemikiran audiens, komunikatorrnya bisa sama namun penilaian audiens terhadap komunikator dan terhadap pesan yang disampaikan bisa sangat berbeda. Sedangkan efektivitas kampanye yang dimaksud dalam penelitian ini adalah perubahan perilaku penggemar K-pop Grup BTS yaitu melakukan donasi ke UNICEF melalui berbagai cara. Menurut teori komunikasi persuasi, walaupun 
persuasi bisa mempunyai efek yang dramatis, tapi tidak selalu persuasi bisa sukses. Kadang-kadang persuasi gagal untuk mempengaruhi sikap atau perilaku. Persuasi melibatkan percobaan untuk dapat mempengaruhi orang lain. Komunikator memiliki niat untuk mengubah sikap atau perilaku orang lain dan harus sadar bahwa dalam percobaan tersebut komunikator mencoba mencapai tujuan dari pesan yang disampaikan (Dudczak, 2001 dalam Perloff, 2017: 24).

Kedua $X_{2} \rightarrow Y$, hubungan antara variabel kualitas pendekatan emosional K-pop Grup BTS $\left(\mathrm{X}_{2}\right)$ terhadap variabel efektivitas kampanye "Love Myself" (Y) ( $\beta=0,078$ dan Sig. 0,130). Nilai signifikansi lebih dari 0,05 yang artinya hipotesis penelitian $\mathrm{H}_{\mathrm{o}}$ diterima, tidak ada pengaruh kualitas pendekatan emosional K-pop Grup BTS terhadap efektivitas kampanye "Love Myself" dan $\mathrm{H}_{\mathrm{a}}$ ditolak, ada pengaruh kualitas pendekatan emosional Kpop Grup BTS terhadap kampanye "Love Myself" sehingga hubungan kedua variabel tersebut tidak signifikan.

Menurut teori retorika, Basil, Ridgway, \& Basil (2008: 3 dalam Perloff 2017: 405) pendekatan dengan rasa bersalah memunculkan empati untuk mempengaruhi individu melakukan perilaku pertolongan selain itu pendekatan dengan rasa bersalah efektif mendorong munculnya rasa tanggungjawab untuk menolong dan mengurangi perasaan bersalah. Berdasarkan data penelitian di kampanye \#ENDViolence \#LoveMyself kualitas pendekatan emosional Kpop Grup BTS yang sudah baik dibuktikan dengan sebagian besar responden yang termasuk kategori tinggi belum cukup mampu mendorong responden untuk mengurangi perasaan bersalah pada saat mengetahui tentang isu kekerasan pada anak dan remaja dengan perubahan perilaku yaitu menolong dengan melakukan donasi.

Ketiga $X_{3} \rightarrow Y$, satu-satunya hubungan yang signifikan bahkan setelah dilakukan uji regresi ulang dalam penelitian ini adalah hubungan variabel kualitas isi pesan K-pop Grup BTS $X_{3}$ terhadap variabel efektivitas kampanye "Love Myself" ( $Y$ ) ( $\beta=0,193 / 0,213$ dan Sig. 0,000). Nilai signifikansi lebih kecil dari 0,05 yang artinya hipotesis penelitian $\mathrm{H}_{\mathrm{a}}$ diterima, ada pengaruh kualitas pendekatan isi pesan K-pop Grup BTS terhadap efektivitas kampanye "Love Myself" dan $\mathrm{H}_{\mathrm{o}}$ ditolak, tidak ada pengaruh kualitas isi pesan $\mathrm{K}$ pop Grup BTS terhadap efektivitas kampanye "Love Myself" sehingga hubungan tersebut signifikan. Menurut teori reorika, Perloff (2017: 340) bukti dapat mempunyai efek di bawah keterlibatan yang rendah namun bekerja melalui proses yang berbeda. Ketika audiens kekurangan motivasi atau ketertarikan pada isu audiens menangkap bahwa isu terdengar impresif karena komunikator menggunakan fakta, statistik, atau testimoni. Bukti bisa muncul untuk memproduksi efek persuasi yang tidak disangka akan stabil. Hal ini terbukti dari hipotesis penelitian yang diterima dan hubungan yang signifikan antara variabel kualitas isi pesan K-pop Grup BTS terhadap variabel efektivitas kampanye "Love Myself" dalam penelitian ini. Bukti statistik, naratif, testimoni, dan visual tentang kampanye \#ENDViolence \#LoveMyself dari BTS mampu memberikan pengaruh kepada responden.

Keempat $X_{1} \rightarrow Z \rightarrow Y$, hubungan antara variabel kredibilitas K-pop Grup BTS $\left(X_{1}\right)$ melalui variabel kategorisasi penggemar (Z) terhadap 
variabel efektivitas kampanye "Love Myself" $(\mathrm{Y})$ ( $\beta$ $=0,026$ dan $-0,032$ dan Sig. 0,447 dan 0,517). Nilai signifikansi lebih dari 0,05 yang artinya hipotesis penelitian $\mathrm{H}_{\mathrm{o}}$ diterima, tidak ada pengaruh kredibilitas K-pop Grup BTS melalui kategorisasi penggemar terhadap efektivitas kampanye "Love Myself" dan $\mathrm{H}_{\mathrm{a}}$ ditolak, ada pengaruh kredibilitas K-pop Grup BTS melalui kategorisasi penggemar terhadap efektivitas kampanye "Love Myself" sehingga hubungan tersebut tidak signifikan. Kategorisasi penggemar dalam penelitian ini dimaksudkan sebagai variabel antara yang artinya followers akun Twitter @armyindonesiaa2 menjadi penting, dari variabel eksogen (kredibilitas) untuk mengetahui apakah memberikan pengaruh terhadap variabel endogen (efektivitas kampanye). Berdasarkan hasil penghitungan analisis jalur, kategorisasi penggemar tidak memberikan pengaruh terhadap hubungan kedua variabel tersebut karena hal ini dapat disebabkan karena responden (followers akun Twitter @armyindonesiaa2) yang memberikan jawaban dalam penelitian ini termasuk theatregoer yaitu penggemar yang mendukung individu atau kelompok karena ingin mencari hiburan semata. Hal ini seperti yang diungkapkan Smith \& Stewart (2008: 82) bahwa tidak selamanya menjadi penggemar berbanding lurus dengan loyalitas di mana ada penggemar yang menyukai satu K-pop grup karena sedang populer atau hanya mencari hiburan semata. Kelima $\mathrm{X}_{2} \rightarrow \mathrm{Z} \rightarrow \mathrm{Y}$, hubungan antara variabel kualitas pendekatan emosional K-pop Grup BTS $\left(X_{2}\right)$ melalui variabel kategorisasi penggemar (Z) terhadap variabel efektivitas kampanye "Love Myself" ( $Y$ ) ( $\beta=0,009$ dan $-0,032$ dan Sig. 0,447 dan 0,517). Nilai signifikansi lebih dari 0,05 yang artinya hipotesis penelitian $\mathrm{H}_{0}$ diterima, tidak ada pengaruh kualitas pendekatan emosional K-pop Grup BTS melalui kategorisasi penggemar terhadap efektivitas kampanye "Love Myself" dan $\mathrm{H}_{\mathrm{a}}$ ditolak, ada pengaruh kualitas pendekatan emosional K-pop Grup BTS melalui kategorisasi penggemar terhadap efektivitas kampanye "Love Myself" sehingga hubungan tersebut tidak signifikan.

Menurut Backer dkk (1992 dalam Siegel \& Elisa, 2013: 334) pendekatan emosional bisa menjadi positif atau negatif, pendekatan emosional positif menyebabkan audiens terkoneksi untuk melakukan perubahan perilaku dengan perasaan yang baik ketika audiens tidak familiar atau bingung tentang suatu isu dan dapat menjadi strategi yang bagus untuk membingkai perubahan sosial sedangkan untuk pendekatan emosional negatif melalui rasa takut dapat berkerja dengan baik ketika penyampaian pesan secara sukarela. Penggemar yang masuk dalam kategori theatregoer (followers akun Twitter @armyindonesiaa2) yang terbanyak dalam penelitian juga menjelaskan bahwa belum ada kedekatan emosional antara K-pop Grup BTS dan responden sehingga belum mampu memberikan pengaruh untuk mengubah perilaku responden untuk melalukan donasi ke UNICEF. Pendekatan emosional K-pop Grup BTS merupakan pendekatan emosional positif yaitu melalui perasaan bersalah yang memunculkan empati, simpati, rasa tanggung jawab, dan rasa ingin menolong namun karena responden belum terlalu terikat secara emosional dengan BTS maka responden belum tergerak untuk mengurangi 
perasaan bersalah ketika mengetahui tentang isu kekerasan pada anak dan remaja dengan cara donasi.

Keenam $\mathrm{X}_{3} \rightarrow \mathrm{Z} \rightarrow \mathrm{Y}$, hubungan antara variabel kualitas isi pesan K-pop Grup BTS $\left(X_{3}\right)$ melalui variabel kategorisasi penggemar ( $Z$ ) terhadap variabel efektivitas kampanye "Love Myself" $Y$ ) ( $\beta=0,048$ dan -0,032 dan Sig. 0,365 dan $0,517)$. Nilai signifikansi lebih dari 0,05 yang artinya hipotesis penelitian $\mathrm{H}_{0}$ diterima, tidak ada pengaruh kualitas isi pesan K-pop Grup BTS melalui kategorisasi penggemar terhadap efektivitas kampanye "Love Myself" dan $\mathrm{H}_{\mathrm{a}}$ ditolak, ada pengaruh kualitas isi pesan K-pop Grup BTS melalui kategorisasi penggemar terhadap efektivitas kampanye "Love Myself" sehingga hubungan tersebut tidak signifikan.

Hubungan yang tidak signifikan sama seperti hubungan variabel sebelumnya karena kategorisasi penggemar yang menyukai BTS untuk mencari hiburan semata sehingga responden (followers akun Twitter @armyindonesiaa2) memiliki kebebasan untuk menerima pesan atau tidak tentang kampanye \#ENDViolence \#LoveMyself yang disampaikan oleh BTS. Responden memiliki kebebasan dengan perilaku mereka karena belum ada ikatan yang kuat antara idola (BTS) dan responden (penggemar). Hal ini menjelaskan argumen D. Joel Whalen (perloff, 2017: 25) bahwa komunikator tidak dapat memaksa audiens untuk terpersuasi, komunikator hanya mampu mengaktifasikan keinginan penerima pesan dan alasan rasional dibalik tujuan kampanye. Komitmen penerima pesanlah yang mampu menggerakkan perubahan perilaku ketika mereka sepenuhnya mengerti dan setia terhadap komunikator.

Ketujuh $Z \rightarrow Y$, hubungan antara variabel kategorisasi penggemar (Z) terhadap variabel efektivitas kampanye "Love Myself" ( $Y$ ) ( $\beta=-0,032$ dan Sig. 0,517). Nilai signifikansi lebih dari 0,05 dan hubungan kedua variabel ini tidak signifikan dan tidak terdapat di hipotesis penelitian karena hanya untuk mengetahui nilai analisis jalur variabel kategorisasi penggemar terhadap variabel endogen $\left(e_{1}\right)$ - efektivitas kampanye "Love Myself" sehingga ikut dalam penghitungan.

Berdasarkan pengujian model secara manual apakah model akhir lebih fit atau tidak dibandingkan hipotesis model didapatkan $\chi_{a}^{2}$ $(3,470)<\chi_{\text {tabel }}^{2}(3,841)$. Artinya secara statistik model akhir tidak signifikan menjadi model fit yang lebih baik dari hipotesis model. Terdapat penambahan nilai kontribusi variabel kualitas isi pesan K-pop Grup BTS terhadap variabel efektivitas kampanye "Love Myself" ( $\beta=0,193 \rightarrow$ 0,213 ) namun hal ini tidak memberikan pengaruh yang berarti di mana terdapat 6 hubungan yang tidak signifikan. Hipotesis model mempunyai peluang untuk menjadi model fit penelitian yang baik dengan mempertimbangkan kembali pola hubungan variabel-variabel penelitian.

Penghitungan total effect (direct effect dan indirect effect) total effect untuk membentuk variabel efektivitas kampanye "Love Myself" sebesar 0,295344. Hubungan langsung (direct effect) yang signifikan memberikan kontribusi yang besar sehingga total effect terbesar tetap pada pembentukan variabel efektivitas kampanye "Love Myself". Hal ini membuktikan hipotesis terakhir $\mathrm{X}_{1} \mathrm{X}_{2} \mathrm{X}_{3} \rightarrow \mathrm{Y}$, bahwa $\mathrm{H}_{\mathrm{a}}$ diterima yaitu ada pengaruh kredibilitas, pendekatan emosional, dan 
kualitas isi pesan K-pop grup BTS terhadap efektivitas kampanye "Love Myself".

Namun walaupun $\mathrm{H}_{\mathrm{a}}$ diterima diperlukan peningkatan kredibilitas (ethos) dan emosional (pathos) dari K-pop Grup BTS agar efek persuasi dalam kampanye \#ENDViolence \#LoveMyself memberikan total effect yang lebih besar (efektivitas meningkat).

\section{KESIMPULAN}

Tujuan penelitian ini adalah (1) mengetahui pengaruh kredibilitas K-pop Grup BTS terhadap efektivitas kampanye "Love Myself"; (2) mengetahui pengaruh kualitas pendekatan emosional yang dilakukan K-pop grup BTS terhadap efektivitas kampanye "Love Myself"; (3) mengetahui pengaruh kualitas isi pesan dari Kpop grup BTS terhadap efektivitas kampanye "Love Myself". Kredibilitas, kualitas pendekatan emosional, dan kualitas isi pesan sebagai variabel eksogen dan efektivitas kampanye "Love Myself" sebagai variabel endogen dan terdapat variabel antara yaitu kategorisasi penggemar. $\mathrm{P} r \mathrm{o} \mathrm{s}$ e $\mathrm{s}$ penelitian kepada 395 responden melalui kuesioner online dan analisa data melalui analisis jalur disimpulkan bahwa tidak ada pengaruh kredibilitas K-pop grup BTS terhadap efektivitas kampanye "Love Myself" dan tidak ada pengaruh pendekatan emosional yang dilakukan K-pop grup BTS terhadap efektivitas kampanye "Love Myself" serta variabel kategorisasi penggemar yang memberikan kontribusi minus pada variabel efektivitas kampanye "Love Myself". Hal ini disimpulkan berdasarkan data yang diperoleh dari responden tanpa mengetahui karakteristik responden apakah pernah mengalami kekerasan atau tidak.

Tujuan penelitian ketiga terlihat adanya pengaruh antar hubungan variabel yaitu variabel kualitas isi pesan dari K-pop Grup BTS terhadap variabel efektivitas kampanye "Love Myself". Dapat disimpulkan bahwa dalam kampanye \#ENDViolence \#LoveMyself yang dilakukan oleh BTS perlu adanya peningkatan kredibilitas dan kualitas pendekatan emosional sehingga penilaian responden (penggemar) lebih meningkat dan menjadi tertarik, termotivasi, dan berkomitmen untuk melakukan perubahan perilaku dirinya untuk melakukan sesuatu yang "wajib" dan "harus" dalam mendukung kampanye \#ENDViolence \#LoveMySelf seperti berdonasi.

Hasil dari penelitian ini memberikan kontribusi teoritik tentang evaluasi pandangan bagi teori retorika yang digunakan dalam kampanye sosial bahwa kredibilitas komunikator belum tentu memberikan pengaruh untuk efektivitas kampanye sosial begitu pula dengan sisi pendekatan emosional belum tentu memberikan pengaruh untuk efektivitas kampanye sosial sehingga memberikan peluang untuk penelitian selanjutnya berkaitan dengan kredibilitas, pendekatan emosional, dan efektivitas kampanye sosial. Hasil penelitian ini tentu berbeda dengan hasil penelitian-penelitian sejenis yang telah ada selama ini di mana kredibilitas dan pendekatan emosional berpengaruh untuk efektivitas kampanye sosial atau terjadi perubahan perilaku pada audiens sasaran sehingga penelitian ini memberikan sisi 
pandang yang lebih luas terkait teori retorika (ethos, pathos, dan logos).

Hasil penelitian ini juga memberikan kontribusi konseptual tentang pandangan bagaimana kampanye "Love Myself" berjalan di Indonesia di antara para penggemar K-pop Grup BTS. Penggemar BTS di Indonesia sebagian besar belum memberikan kontribusi terhadap efektivitas kampanye "Love Myself" di mana para penggemar belum tergerak untuk melakukan donasi hal ini juga pengaruh dari para penggemar yang belum sampai pada tahap terikat dan loyal pada BTS sehingga diperlukan adanya peningkatan dari sisi kredibilitas dan pendekatan emosional dari BTS kepada penggemar terutama terkait kampanye "Love Myself".

\section{DAFTAR PUSTAKA}

Bruner, Raisa. (2019, October 8). The Mastermind Behind BTS Opens Up About Making a Kpop Juggernaut. TIME. https://time.com/5681494/bts-bang-sihyuk-interview/. Akses: 16 Juli 2021.

Byrum, K. L. (2014). A comparison of the source, media format, and sentiment in generating source credibility, information credibility, corporate brand reputation, purchase intention, and social media engagement in a corporate social responsibility campaign presented via social media (Order No. 3636772). Available from ABI/INFORM Collection. (1616654089). https://search. proquest.com/docview/1616654089?acco untid=44396. Akses: 22 Juli 2019.

Dwi, Kris. (2021, April 3). Sering Bingung, Kenapa
Army disebut Fandom Toxic?. Sanepo. https://sanepo.com/kenapa-armydisebut-fandom-toxic/. Akses: 18 Juli 2021. Gerintya, Scholastica. (2017, Nov 21). 73,7 Persen Anak Indonesia Mengalami Kekerasan di Rumahnyah Sendiri Tirto.id. https:// tirto.id/737-persen-anak-indonesiamengalami-kekerasan-di-rumahnyasendiri-cAnG. Akses: 5 Juli 2019.

GLOBAL STATUS REPORT ON VIOLENCE PREVENTION 2014. World Health Organization. Luxemburg, 2014. https:// www.who.int/violence_injury_prevention/ violence/status_report/2014/en/. Akses: 31 Mei 2019.

Griffin, Em., Ledbetter, Andrew., \& Sparks, Glenn. (2015). A First Look at Communication Theory (Ed. 9th). NY: McGraw-Hill.

Howard, J. C. (2017). Tweeting is easy, rhetoric's harder: A rhetorical analysis of public political discourse on social media (Order No. 10687269). Available from Publicly Available Content Database. (1984598389). Retrieved from https://www.proquest. com/dissertations-theses/tweeting-iseasy-rhetorics-harder-rhetorical/docview $/ 1984598389 /$ se -2 ? accountid $=44396$. Akses: 1 April 2021

Lumsden, Gay \& Lumsden, Donald. (2006). Communication with Credibility and Confidence (3rd Ed.) New York: Wadsworth, Cengage Learning.

Muyasaroh, Siti. (2013). KAMPANYE PERUBAHAN SOSIAL: Kesadaran Masyarakat, Aspek Perubahan Kognitif dan Prilaku. https://jurnal.yudharta.ac.id/v2/index.ph 
p/HERITAGE/article/download/831/685.

Akses: 7 Juli 2019

Olobatuyi, Moses E. (2016). AUser's Guide to

Path Analysis. Lanham: U n i v e r s i t y Press Of America.

Perloff, Richard M. (2017). THE DYNAMICS PERSUASION: Communication and Attitudes in the 21st Century (Ed. 6th). New York: Routledge.

Rahardjo, T., Handoko, S., Manurung, P., Listorini, D., Rejeki, MC. S., Putranto., A, Herawati, F. A. (2004). Metode Penelitian Komunikasi - Teori dan Aplikasi. Yogyakarta: Gitanyali.

Ramadhani, Yulaika. (2018, Des 6). 10 Tagar \& Akun KPOP Terpopuler twitter 2018: BTS Hingga Blackpink. Tirto.id. https://tirto.id/10-tagar-terpopulertwitter-2018-bts-recehkantwittersampai-exo-da8R. Akses: $18 \mathrm{Juli} 2021$.

Ramadhani, Yulaika. (2018, Des 6). 10 Tagar Terpopuler Twitter 2018, \#BTS \#RecehkanTwitter Sampai \#EXO. Tirto.id. https://tirto.id/10-tagar-akun-kpopterpopuler-twitter-2018-bts-hinggablackpink-da8V. Akses: 18 Juli 2021.

Ramage, John D., Bean. John C., Johnson, June. (2012). Writing Arguments: A Rhetoric with Readings (Ed. 9th). NY: Pearson.

Rice, Ronald E., \& Atkin, Charles K. (2013). Public Communication Campaigns (Ed. 4th). New York: Sage Publications.

Sanjaya, Andika., Biyoga, Suswandoyo, \& Alunaza, Hardi. (2017). Pemimpin Minoritas dan Strategi Retorika Pathos dalam Kampanye: Analisis Isi Deskriptif Pesan
Strategi Retorika dalam Facebook Kampanye Pemilihan Gubernur. Jurnal Komunikasi Indonesia, Volume VI (Nomor 2). https://doi.org/10.7454/jki.v6i2.8917. Akses: 7 Juli 2019.

Siegel, Michael. \& Elisa, A. Resnick. (2013). Marketing Public Health: Strategies to promote Social Change (3rd Ed.). Massachusetts: Jones and Bartlett Publishers.

Smith, Aaron C.T.\& Stewart, Bob (2014). Introduction to Sport Marketing (2nd ed.). London: Routledge

United Nations Children's Fund, A Familiar Face: Violence in the lives of children and adolescents, UNICEF, New York, 2017. https://data.unicef.org/resources/afamiliar-face/. Akses: 2 Mei 2019.

West, Richard \& Turner Lynn H. (2014). Introducing Communication Theory: Analysis and Application (5th Ed.). New York: McGraw-Hill

https://www.love-myself.org/. Akses 3 Juli 2019 


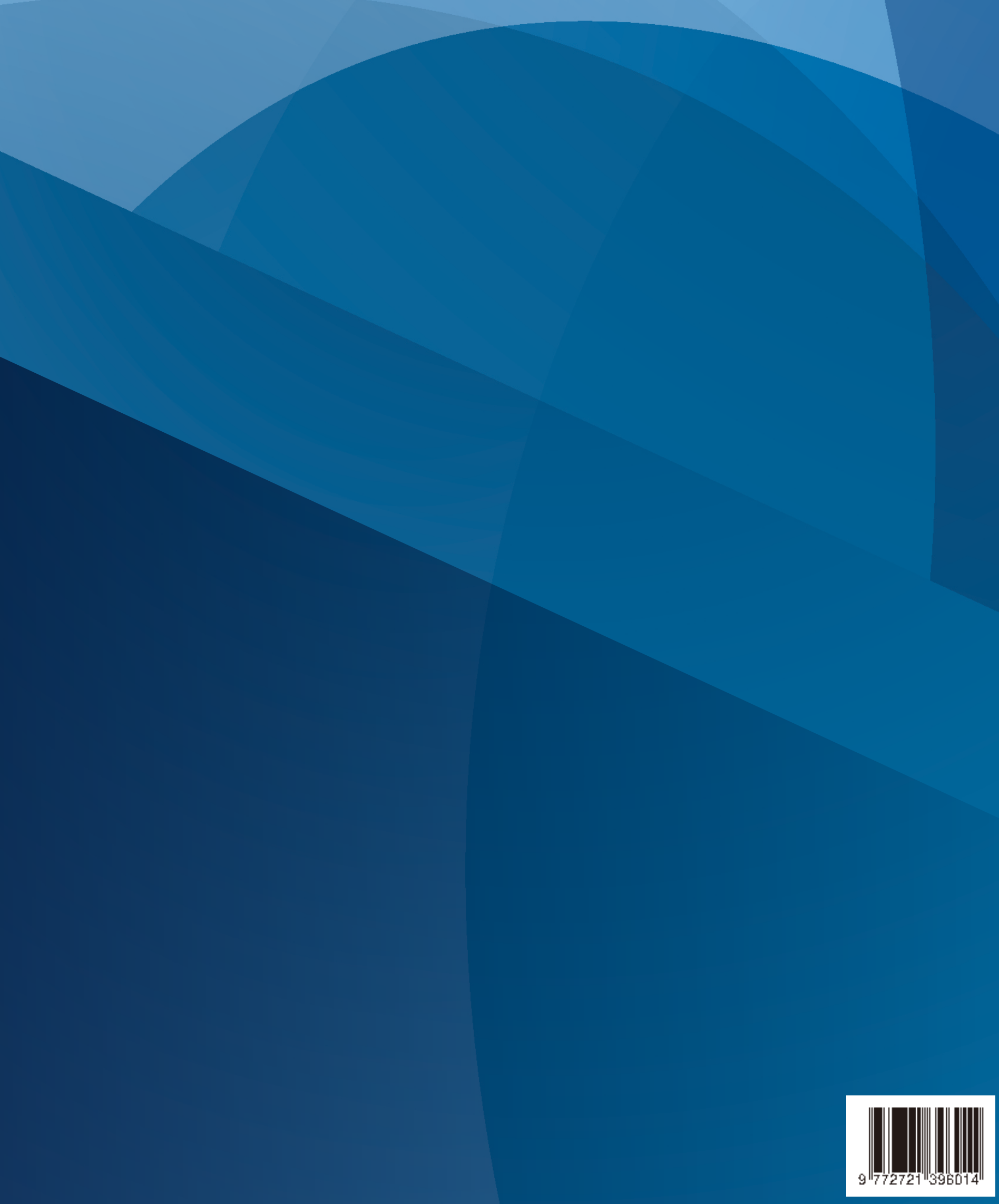

